\title{
Causes, Diagnosis, Risk Stratification and Treatment of Bicuspid Aortic Valve Disease: An Updated Review
}

\author{
Stefanos Sakellaropoulos ${ }^{\mathrm{a}, \mathrm{f}}$, Muhemin Mohammed ${ }^{\mathrm{a}, \mathrm{f}}$, Stefano Svab ${ }^{\mathrm{a}}$, Dimitra Lekaditi ${ }^{\mathrm{b}}$, \\ Panagiotis Sakellaropoulos ${ }^{\mathrm{c}}$, Andreas Mitsis ${ }^{\mathrm{d}, \text { e, }} \mathrm{g}$
}

\begin{abstract}
The most common congenital heart disease is the bicuspid aortic valve. Understanding the pathophysiology and the altered hemodynamics is a key component for the diagnosis, risk stratification and treatment. Among others, aortic valve stenosis is the most common complication. Treatment strategies vary depending on the severity of the disease, particularly the dilation of the aorta playing a major role. Together with valve replacement, transcatheter aortic valve implantation is now considered as an alternative option with good results. With this review we would like to discuss the causes, diagnostic methods, risk stratification and treatment strategies of the bicuspid aortic valve.
\end{abstract}

Keywords: Bicuspid aortic valve; Aortic stenosis; Aortic insufficiency; Aortic dilatation; Aortic dissection

\section{Introduction}

The aortic valve is located at the end of the outflow tract of the left heart, and has three pocket-shaped leaflets. Commissure is the area of contact of the two adjacent flap pockets, in which the upper part of the leaflets is attached to the wall of the aorta. Above the aortic valve, the wall of the aorta ends to the sinuses of Valsalva. The coronary vessels originate from the sinuses of Valsalva; from the associated right sinus originates the right

Manuscript submitted April 3, 2020, accepted April 9, 2020

Published online June 3, 2020

aSwiss Cardiovascular Centre, Cardiology, Bern University Hospital, Bern, Switzerland

${ }^{b}$ Department of Pediatrics, Kantonspital Aarau, Aarau, Switzerland

'Internal Medicine Department, Agios Savvas General Hospital of Athens, Greece

${ }^{\mathrm{d} C a r d i o l o g y}$ Department, Nicosia General Hospital, 2029, Nicosia, Cyprus

${ }^{e}$ Cardiology and Aortic Centre, Royal Brompton and Harefield NHS Foundation Trust, London SW3 6NP, UK

${ }^{\mathrm{f}}$ They have equally contributed to this article.

${ }^{g}$ Corresponding Author: Andreas Mitsis, Cardiology Department, Nicosia General Hospital, Cardiology Department, 2029, Nicosia, Cyprus. Royal Brompton Hospital, Cardiology and Aortic Centre, London SW3 6NP, UK. Email: andymits7@gmail.com

doi: https://doi.org/10.14740/cr1061 coronary vessel and from the left sinus the left coronary vessel. The third cusp is the non-coronary sinus [1].

An exception is the bicuspid aortic valve (BAV), which was recognized early by Paget. A distinction is made between the bicuspid valve, which is characterized by the attachment of only two valve leaflets and two sinuses, and the more frequent "bicuspid" valve, in which anatomically three sinuses and flap pockets are created, but two are fused [2].

In the BAV with two sinus of Valsalva, there are two cusps oriented either anterior-posteriorly with commissure running from left to right, or laterally with commissure running from anterior to posterior. This is the true BAV. More commonly, the BAV has three sinuses of Valsalva. In this scenario, one cusp is larger than the second, and has a central thickening (raphe) [3].

These valves are formed by the pre- or postnatal fusion of two cusps of a primary tricuspid valve or with three applied sinuses. This results in a so-called functional BAV. Postnatal fused cusps are acquired BAVs. The raphe with unequal cusps can be found in different orientations, depending on which cusps are unified, with most frequent the right and left cusps [3].

\section{Prevalence}

The etiology of this condition is not known exactly. The vast majority arises as an isolated birth defect. Furthermore, there are genetic causes. The first reported genetic case of BAV was Anderson syndrome (additionally characterized by ventricular arrhythmias, periodic paralysis, dysmorphic facies, cleft palate, and scoliosis) [4]. However, genetic causes without syndrome have also been identified. The study by Garg et al has shown that a NOTCH1 mutation in the signal and transcriptional regulator is responsible for the development of BAV [4].

Furthermore, the importance of the extracellular matrix was investigated. The matrix proteins play a role in the differentiation of the cells and formation of the leaflets [5]. Here, microfibrillar proteins play a role in the transformation of mesenchymal cells into mature flap cells. They serve as a scaffold for the embryonic cells [5].

\section{Genetic Background}

There are a few reports of familial accumulations of BAV disease. Glick and Roberts reported a prevalence of aortic valve 
disease of $24 \%$ in families with more than one person with aortic disease, suggesting a Mendelian inheritance pattern. Determination of the genetics of BAV is complex, and recent studies have shown that BAV is likely due to mutations in different genes with different patterns of inheritance [6]. Signaling and transcriptional signaling mutations of NOTCH1 (gene map locus 9q34.3) lead to abnormal aortic valve development, and later to suppression of calcium deposition. Thus, there is a link between the genetic abnormality, abnormal morphogenesis and subsequent progression of the disease [7].

Although further studies are needed to establish genetic screening, previous clinical studies have reported a $9 \%$ prevalence of BAV in first-degree relatives of patients with BAV. Based on these data and experts' opinion, according to the current American College of Cardiology (ACC)/American Heart Association (AHA) guidelines, echocardiographic screening for BAV is recommended in first-degree relatives of patients with BAV [8].

\section{Diagnosis}

Auscultatory findings include a systolic ejection click. An associated murmur of aortic stenosis (AS) may occur. Concomitant aortic insufficiency in these lesions could be present. A transthoracic echocardiography can usually confirm the diagnosis with a sensitivity of $92 \%$ and specificity of $96 \%$.

Sometimes a differentiation is difficult between BAV and unicuspid aortic valve, however, is especially important for preoperative evaluation. During diastole, raphe of the valve can visually make the valve appear as tricuspid. In diastole, the opening has characteristic "fish" morphology. In case of unsecured diagnosis transesophageal echocardiography should be performed.

Furthermore, precise diagnosis could be performed using alternative cardiac imaging, such as magnetic resonance imaging (MRI) or computed tomography (CT), to confirm BAV anatomy, but especially for aortic imaging.

\section{Echocardiography and Global Longitudinal Strain}

Left ventricular ejection fraction (LVEF) is an important echocardiographic prognostic marker in patients with valvular heart disease and an important determinant of clinical decision making in these patients.

Zhang et al [9] reported in 32 BAV patients with varying severity of valve dysfunction, and found that aortic regurgitation (AR) (either as an isolated lesion or in combination with AS) was associated with greater impairment of global function compared to patients with normal valve function; and in BAV patients with mixed valve functions AS and AR showed a greater impairment of LVGLS than the normal valve functional group.

In addition, Stefani et al [10] showed a trend towards greater impairment of LVGLS in 20 young athletes with BAV and mild AR compared to normal subjects despite normal LVEF.
The group with the greatest impairment of LVGLS consisted of patients with moderate and severe mixed AS and AR, followed by patients with moderate and severe isolated AS and isolated AR. These groups are characterized by different patterns of LV transformation in response to different pressure and volume overloads.

The group of patients with moderate and severe isolated AR is characterized by a larger LV mass index due to LV dilation and increase in LV wall thickness in response to volume and pressure overload, whereas the group of patients with moderate and severe AS has smaller LV dimensions and a smaller greater relative wall thickness as a reaction showed pressure overload.

While AR is associated with the growth of cardiomyocytes with the addition of new sarcomeres in series and interstitial fibrosis [11], AS is associated with an increase in muscle fiber diameter with parallel addition of new myofibrils and an increase in interstitial fibrosis and myocyte apoptosis, partly as a consequence of oxygen supply requirement mismatch and myocardial ischemia [12].

\section{Risk Stratification}

The clinical course of BAV aortopathy is related to the rapidity of progression and the incidence of acute aortic events. The clinical pictures may take the form of an indolent chronic disease, harmless to the patient's life expectancy, while others may manifest as acute complications. It is believed that the prognosis heterogeneity results from a complex, multifactorial pathogenesis, where different relative contributions are involved, including several possible genetic variants and different flow-related mechanisms [13].

Assuming that the phenotypic heterogeneity is caused by the same pathogenesis, defining the phenotype may be a tool to identify individual patients who will suffer from the serious forms of the disease in order to conduct personalized surgical decision making. Therefore, a number of studies have attempted to find out the phenotypic diversity of BAV aortopathy [14].

\section{Markers}

The ideal prognostic circulating biomarker of BAV aortopathy should be of pathogenetic importance, reliably measurable in serum/plasma. Furthermore, there should be also a significant concentration difference from the baseline values in healthy subjects, of proven relevance to disease progression (i.e., predictable), progressive dilatation, and/or acute aortic events. Finally and ideally, there should be no or loose correlation between the markers and the aortic diameter, in order for the markers to provide additional prognostic layering information in addition to this parameter.

The search for circulating biomarkers in the context of BAV aortopathy is currently a novel field of research. Among the biomarkers for BAV aortopathy, some studies are focused mainly on circulating proteins belonging to different pathways or on noncoding circulating ribonucleic acid molecules 
(RNA), including microRNAs (miRNAs) and long noncoding RNAs [15].

A negative correlation was found between alpha-1-antitrypsin (a common serine protease inhibitor that can protect tissue from inflammatory cell enzymes) and aortic diameter in the study of Kilickesmez et al [16].

Interestingly, one study found that high concentrations of circulating soluble receptor for advanced glycation end product (sRAGE) are associated with the presence of BAV and aortopathy with altered aortic microstructure independent of aortic diameter, and are directly correlated [17].

An elevated plasma level of asymmetric dimethylarginine (ADMA) was found in non-stenotic BAV patients with dilated aorta. Although this study concluded that plasma ADMA levels could be proved to be of prognostic value, it failed to conduct a follow-up study to validate this hypothesis. Among the proteins studied to date are potential biomarkers for BAV aortopathy, the pathway of transforming growth factor-b (TGF-b) is attracting attention due to its role in fibrosis, inflammation, cell proliferation and migration, as well as extracellular matrix remodeling and its involvement in aortopathy syndromes, like Loeys-Dietz and Marfan syndrome [18].

A strong relationship between plasmatic TGF-b1 and the soluble form of its co-receptor endoglin (sENG) is linked, and this is indicative of an adverse aortic signature and a propensity to aortopathy progression in BAV patients with AS and unexpanded aortic ascending over a 3-year follow-up, thus supporting the potential prognostic value [19].

So far, this is the only study that substantiates the relevance of the candidate biomarker to the progression of aortic disease (namely, the aortic growth rate over time). Differences in serum TGF-b1 levels between BAV patients and patients without a defined genetic aortic syndrome were also identified.

Regarding RNA molecules, current data support expression of miRNAs in homeostasis of endothelial and smooth muscle cells and phenotypic changes associated with the progression of aortopathy [20]. MiRNAs are generally considered to be ideal disease biomarkers because of their plasma levels reproducible, stable, and consistent among subjects, as they are protected from endogenous ribonuclease-induced degradation [21].

\section{Clinical Course}

Although the clinical presentation of patients with BAV may be varied from mild to severe valve disease, symptoms typically develop in adulthood. The clinical manifestations refer to the function of the aortic valve, the aortopathy and acquired complications such as endocarditis. In childhood, BAV disease is often asymptomatic.

It is estimated that only one in 50 children are clinically affected. At some point in adulthood, abnormal shear stress occurs, leading to valve calcification and, in some cases, further aortic root dilatation [22].

Estimates of the prevalence of complications and outcomes vary according to the age of the study, the selected cohort, and the method for the diagnosis of BAV (clinical exami- nation vs. cardiac catheterization, echocardiography) [23].

\section{Complications}

\section{Infectious endocarditis}

Between $10 \%$ and $30 \%$ of patients with BAV will experience infective endocarditis during their lifetime. Deposits, abscesses or perforations on the valve leaflets or the myocardium are the result of the infection. On the other hand, BAV is diagnosed in $25 \%$ of cases with infectious endocarditis [24]. Infectious endocarditis of BAV is more common in younger patients. Furthermore, it was shown that there is a clear dominance of the male sex (73-100\%).

\section{Aortic dilatation, aortic dissection and coarctation}

The BAV is associated with the development of dilatation in the aorta, especially the aortic root and ascending aorta. It is discussed whether it is an expansion due to an abnormal hemodynamic load on the wall of the aorta due to the malformation of the valve, or whether it was caused by a common defect in the development of the aortic valve and wall [25]. One reason for the susceptibility in this area is the presence of a different activity of the matrix metalloproteinases 2 and 9. These are endopeptidases that have a function in the turnover of the cell matrix. For the matrix metalloproteinases, higher activity in the wall of the aneurysms of patients with BAV compared to those of patients with tricuspid aortic valve has been demonstrated. Histologically, there is a cystic median necrosis in the area of the aorta. Here it comes to degeneration of the media, with subsequent cavitation [26].

Coarctation of the aorta and the BAV often occurs simultaneously, so the aortic coarctation should be removed as a distinct disease and instead considered as part of a generalized aortopathy. A BAV itself is often associated with an abnormal aortic structure that predisposes to aortic dilatation and aneurysmal formation.

Young patients have unique risk factors for dissection compared to elderly patients with dissection: Marfan syndrome, BAVs and larger aortic dimensions. Surprisingly, the mortality risk for young patients is no less than that for older patients [27].

It was also shown that acute type A aortic dissection in the settings of BAV is more common in the black population $(52.4 \%$ vs. $39.3 \%)$ than white population. Black patients are younger (mean age $54.6 \pm 12.8$ years vs. $64.2 \pm 15.2$ years), and more frequently have a history of cocaine abuse $(12 \%$ vs. $1.6 \%)$, high blood pressure $(89.7 \%$ vs. $73 \%)$ and diabetes (13.2\% vs. $6.4 \%$ ) [28].

With regard to dilation of the aorta, the prevalence of section of the aorta is dependent. In one study, the prevalence of root dilation was reported to be $7.5 \%$ in men and $16.7 \%$ for ascending aorta [29]. A life-threatening complication is an aneurysm dissection, with a nine times higher risk than TAV [30].

By the end of the second decade of life, most flaps al- 

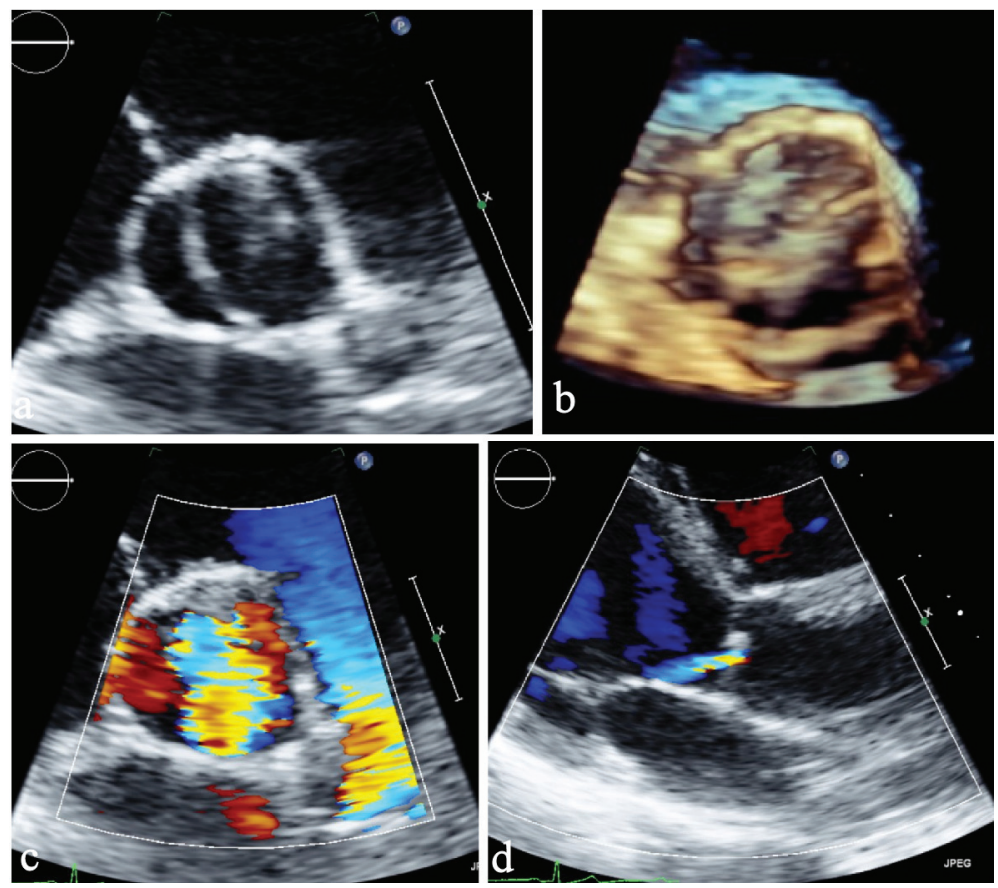

Figure 1. (a) Parasternal short axis view. (b) Parasternal short axis view (3D). (c) Parasternal short axis view of color Doppler showing severe aortic insufficiency. (d) Parasternal long axis view showing eccentric jet of regurgitant flow typical by BAV. BAV: bicuspid aortic valve; 3D: three-dimensional.

ready show age-related changes such as calcification, fibrosis or thickening [30].

A congenital BAV is calculated as an additional risk factor for the calcification of the aortic valve. It has generally been assumed that patients with calcification are more likely to suffer from degenerative aortic valve disease than patients with a tricuspid aortic valve [31]. The study by Robicsek et al has shown that a fully opened BAV in the middle systole results in an asymmetric opening area and thus does not lead to a stenosis, but also to altered formation in the ascending aorta [32]. There is thus a correlation between BAV and the occurrence of aortic aneurysms. Approximately $30 \%$ of all patients with calcification do not suffer from clinical manifestation until old age [33]. All others become symptomatic throughout life.

\section{Aortic valve stenosis}

Aortic valve stenosis is the most common complication of the BAV [34]. The incidence of stenosis in patients with BAV is between $59 \%$ and $81 \%$ based on various studies [35]. Even a BAV, characterized by two equally sized, symmetrically arranged leaflets, is at risk for development of stenosis or anatomy and morphology for functional stenosis.

Except for the hemodynamic characteristics of the functional stenosis, calcification plays a major role. In the autopsy study by Sabet et al, at least a moderate calcification was demonstrated in $99 \%$ of stenotic aortic valves [35]. The calcification of the aortic valve begins in the second decade of life. Larger deposits on the valve in patients less than 30 years old are unusual, but there is no stenosis without calcifications be- fore the third decade of life.

\section{Aortic valve regurgitation}

Due to an incomplete valve closure, an insufficiency leads to a diastolic flow reversal. The causes for this are ring dilatation or prolapse, dilatation of the aortic root or infective endocarditis. The cases of aortic insufficiency shows a lower calcification compared to AS [35]. In fact, however, an insufficiency may be due to calcification, as part of a fixation of the leaflet in an open position. Acute aortic valve insufficiency arises in most cases as a result of infectious endocarditis. After healing in some cases of undiscovered endocarditis, there is chronic insufficiency. Based on several studies, AR requires a surgical treatment sooner compared to AS, or the mean age is 46 years and 63 years, respectively [35] (Fig. 1a-d).

\section{Medical Treatment}

At a minimum, hypertension should be aggressively treated in patients with BAV disease. In Marfan-associated aortopathy, treatment with beta-blockers to slow the rate of progression, however, is the standard of care in many centers [36].

The ACC/AHA guidelines for the treatment of congenital heart disease in adults and guidelines for the treatment of patients with valvular heart disease suggest that it makes sense to use beta-blockers in this population (class IIa recommendation). There are emerging data regarding the use of angiotensinconverting enzyme inhibitors (ACEIs) and the use of angioten- 
sin II receptor blockers to reduce aortic root dilation in Marfan syndrome [37]. Furthermore, the AT-II blocker irbesartan is found to be associated with a decrease in the rate of aortic dilatation in children and young adults with Marfan syndrome and could reduce the incidence of aortic complications [38].

Whether or not the aforementioned drugs play a role in BAV aortopathy has ultimately not been clearly demonstrated. Finally, long-term vasodilator therapy is recommended for BAV disorders with aortic insufficiency only if systemic hypertension is present at the same time.

The role of treatment with cholesterol-lowering drugs is unclear. Although some studies [39] have shown a slowing of the progression of aortic valve disease, one large prospective randomized study has shown that this treatment stopped the progression of the disease in calciferous AS.

The use of lipid-lowering drugs has not been studied in young patients with BAV. The current ACC/AHA guidelines for the management of patients with valvular heart disease do not advocate the use of statins to slow down the degenerative process in this population.

\section{Interventions}

In pediatric population, decision making is complex and has a great impact for the rest of life. Particularly in neonates with severe stenosis, decision making of surgical vs. balloon valvuloplasty is under questioning and clearly depends on centers' experience. Furthermore, in children and adolescents, based on contemporary literature, the Ross procedure is the optimal AV replacement option, as it provides optimal growth, hemodynamics, and decreased rate of endocarditis as well as thromboembolism. Symptomatic AS is an indication for intervention similar to the standard indication for degenerative tricuspid valve disease. In the pediatric setting, indication for intervention is symptomatic children with peak-to-peak gradients of $50 \mathrm{~mm} \mathrm{Hg}$. Additionally, asymptomatic children with peakto-peak gradients of $60 \mathrm{~mm} \mathrm{Hg}$ should be considered for intervention. Good mid-term results after balloon valvuloplasty have been demonstrated in experienced centers [40].

In cases where aortic regurgitation develops following balloon valvuloplasty, aortic valve replacement may be necessary. In adulthood the aortic valve replacement is most commonly the joint intervention performed for either aortic valve stenosis or insufficiency.

Surgery for BAV disease occurs at an earlier age than that for degenerative tricuspid aortic disease. In the Olmsted County series, the mean age for BAV surgery is $40-20$ years vs. 67 - 16 years for patients with tricuspid aortic valve [41].

Indications for intervention in AS or incompetence are similar to those described for tricuspid valve disease. Approximately $30 \%$ of adults with aortic valve replacement also require aortic root surgery.

Over the last years, except for open heart surgery, transcatheter aortic valve implantation (TAVI) emerges as an alternative option for the treatment of BAV disease. Although the outcomes of TAVI in BAV were not optimal in first-generation devices, new generation devices lead to improvement.
Factors that suggest operative management are: a small European System for Cardiac Operative Risk Evaluation (EuroSCORE) risk $(<4 \%$ ), no comorbidities, age of $<75$ years, a favorable rehabilitation process, suspicion of endocarditis, unfavorable access for a TAVI procedure, a small distance between coronary artery ostium and aortic annulus, thrombus in aorta or left ventricle, an operable coronary artery disease or heart valve disease, an aneurysm of aorta ascendens and finally in case of hypertrophic cardiomyopathy with an indication for myectomy.

\section{BAV and Pregnancy}

During pregnancy there are changes in the hemodynamics as well as changes in the aortic media. There is an increased risk especially in women with BAV and significant AS and/ or dilatation. Recent studies describe that the risk of adverse pregnancy events in women with severe AS is lower than previously described. Although this group of women continues to present a risk group for maternal and fetal morbidity, their overall mortality risk is likely to be $1 \%$ [42-44].

In rare cases, progressive symptoms develop during pregnancy and require surgery, which can be performed during pregnancy, but are associated with both maternal and fetal risks and should only be done if necessary.

Although pregnancy can be successfully completed in most cases, in some of them aortic surgery may be required in women with severe AS early in pregnancy [44-46].

Pregnancy itself appears to accelerate the need for postpartum surgery in women with moderate or severe AS [46]. It is therefore important that women with BAV should be counseled on the risk of pregnancy and the potential for late complications.

\section{Follow-Up}

To track the progression of the disease, serial transthoracic echocardiography should be performed in all patients. An annual cardiac imaging is recommended at least for patients with significant valve lesions or those with aortic root diameter $>$ $40 \mathrm{~mm}$. In these patients without significant heart valve lesions and aortic root diameter $<40 \mathrm{~mm}$, cardiac imaging every 2 years may be sufficient (Table 1).

The aortic root size should be related to the body surface area. A dimension of $2.1 \mathrm{~cm} / \mathrm{m}^{2}$ is the upper limit of normal $[47,48]$. Complete visualization of the thoracic aorta should be performed regularly for monitoring. Because CT is associated with significant radiation exposure, it should only be done in young population when needed, and if other imaging modalities are not available.

Other parameters, such as adherence to the aorta, can be measured by echocardiography or by MRI. The aortic elasticity decreases in patients with BAV and aortic insufficiency, and in the future these physiological measures may play a role in risk stratification [49-51].

In the future, biomarkers for valvulopathy, ventricular re- 
Table 1. Screening and Follow-Up for Patients With BAV

TTE-screening of the aortic root and aorta ascendens for every patient with BAV should be performed. CT and MRI for precision diagnosis in case of inadequate TTE imaging.

If aortic root or aorta ascendens diameter is $>45 \mathrm{~mm}$, or there is increase of $3 \mathrm{~mm}$ per year, follow-up every year is indicated.

In case of a diameter $>50 \mathrm{~mm}$ or there is increase of $3 \mathrm{~mm}$ per year in echocardiography, CT or MRI for confirmation should be performed.

Patients without significant heart valve lesions and aortic root diameter $<40 \mathrm{~mm}$, cardiac imaging every 2 years may be sufficient.

sponse to valvular disease and aortic root disease may be useful. For example, in degenerative aortic valve disease, brain natriuretic peptide has been shown to be prognostically important [51]. Serum markers such as matrix metalloproteinase, amino-terminal propeptide type III collagen, fibrinogen and markers of inflammation are elevated in individuals with aneurysms of the abdominal aorta [52].

BAV: bicuspid aortic valve; TTE: transthoracic echocardiogram; CT: computed tomography; MRI: magnetic resonance imaging.

\section{Acknowledgments}

We thank our colleagues from the University Hospital of Bern and General Hospital of Aarau/Switzerland, General Hospital of Agios Savvas/Greece, General Hospital of Nicosia/Cyprus and Cardiology and Aortic Centre, Royal Brompton and Harefield NHS Foundation Trust, London, UK, who provided insight and expertise that greatly assisted this review.

\section{Financial Disclosure}

This review was not supported by any foundation, grant maker or donor.

\section{Conflict of Interest}

None to declare.

\section{Author Contributions}

Dimitra Lekaditi contributed to insights especially for pediatric population; Panagiotis Sakellaropoulos: insights for complications, especially endocarditis; Muhemin Mohammed: insights especially for diagnostics and cardiac imaging; Stefano Svab: insights especially for clinical course and follow-up; Andreas Mitsis: insights especially for aortopathy, treatment and interventions; Stefanos Sakellaropoulos: main text, insights especially for genetic background, risk stratification, bio-markers.

\section{Data Availability}

Any inquiries regarding supporting data availability of this study should be directed to the corresponding author.

\section{Abbreviations}

ADMA: asymmetric dimethylarginine; AS: aortic stenosis; AR: aortic regurgitation; ACC: American College of Cardiology; AHA: American Heart Association; ACTA2: anabolic catabolic transforming agent 2; BAV: bicuspid aortic valve; CT: computed tomography; GLS: global longitudinal strain; LV: left ventricle; LVEF: left ventricular ejection fraction; MRI: magnetic resonance imaging; RNA: ribonucleic acid; SRAGE: soluble receptor for advanced glycation end product; TAV: tricuspid aortic valve; TAVI: transcatheter aortic valve implantation

\section{References}

1. Arnold G, Beier HM, Herrmann M, Kaufmann P, Kretschmann HJ, Kuhnel W, Schiebler TH, et al. Organe des Kreislaufs. In: Schiebler TH, Schmidt W, Zilles K. Anatomie. 8. Auflage, Springer, Berlin; 1999. p. 516-526.

2. Waller BF, Carter JB, Williams HJ, Jr., Wang K, Edwards JE. Bicuspid aortic valve. Comparison of congenital and acquired types. Circulation. 1973;48(5):1140-1150.

3. Sievers HH, Schmidtke C. A classification system for the bicuspid aortic valve from 304 surgical specimens. J Thorac Cardiovasc Surg. 2007;133(5):1226-1233.

4. Garg V. Molecular genetics of aortic valve disease. Curr Opin Cardiol. 2006;21(3):180-184.

5. Fedak PW, Verma S, David TE, Leask RL, Weisel RD, Butany J. Clinical and pathophysiological implications of a bicuspid aortic valve. Circulation. 2002;106(8):900904.

6. Cripe L, Andelfinger G, Martin LJ, Shooner K, Benson DW. Bicuspid aortic valve is heritable. J Am Coll Cardiol. 2004;44(1):138-143.

7. Martin LJ, Ramachandran V, Cripe LH, Hinton RB, Andelfinger G, Tabangin M, Shooner K, et al. Evidence in favor of linkage to human chromosomal regions $18 \mathrm{q}, 5 \mathrm{q}$ and $13 \mathrm{q}$ for bicuspid aortic valve and associated cardiovascular malformations. Hum Genet. 2007;121(2):275284.

8. Warnes CA, Williams RG, Bashore TM, Child JS, Connolly HM, Dearani JA, Del Nido P, et al. ACC/AHA 2008 guidelines for the management of adults with congenital heart disease: a report of the American College of Cardiology/American Heart Association Task Force 
on Practice Guidelines (Writing Committee to Develop Guidelines on the Management of Adults With Congenital Heart Disease). Developed in Collaboration With the American Society of Echocardiography, Heart Rhythm Society, International Society for Adult Congenital Heart Disease, Society for Cardiovascular Angiography and Interventions, and Society of Thoracic Surgeons. J Am Coll Cardiol. 2008;52(23):e143-e263.

9. Zhang X, Zhu M, He T, Yuan J, Zhu H, Morrisroe DE, Ashraf M, et al. Cardiac mechanics in isolated bicuspid aortic valve disease with normal ejection fraction: a study of various valvular lesion types. Medicine (Baltimore). 2015;94(47):e2085.

10. Stefani L, De Luca A, Maffulli N, Mercuri R, Innocenti G, Suliman I, Toncelli L, et al. Speckle tracking for left ventricle performance in young athletes with bicuspid aortic valve and mild aortic regurgitation. Eur J Echocardiogr. 2009;10(4):527-531.

11. Borer JS, Truter S, Herrold EM, Falcone DJ, Pena M, Carter JN, Dumlao TF, et al. Myocardial fibrosis in chronic aortic regurgitation: molecular and cellular responses to volume overload. Circulation. 2002;105(15):18371842.

12. Hein S, Arnon E, Kostin S, Schonburg M, Elsasser A, Polyakova V, Bauer EP, et al. Progression from compensated hypertrophy to failure in the pressure-overloaded human heart: structural deterioration and compensatory mechanisms. Circulation. 2003;107(7):984-991.

13. Della Corte A, Body SC, Booher AM, Schaefers HJ, Milewski RK, Michelena HI, Evangelista A, et al. Surgical treatment of bicuspid aortic valve disease: knowledge gaps and research perspectives. J Thorac Cardiovasc Surg. 2014;147(6):1749-1757, 1757 e11741.

14. Michelena HI, Della Corte A, Prakash SK, Milewicz DM, Evangelista A, Enriquez-Sarano M. Bicuspid aortic valve aortopathy in adults: Incidence, etiology, and clinical significance. Int J Cardiol. 2015;201:400-407.

15. Rocchiccioli S, Cecchettini A, Panesi P, Farneti PA, Mariani M, Ucciferri N, Citti L, et al. Hypothesis-free secretome analysis of thoracic aortic aneurysm reinforces the central role of TGF-beta cascade in patients with bicuspid aortic valve. J Cardiol. 2017;69(3):570-576.

16. Kilickesmez KO, Abaci O, Kocas C, Yildiz A, Kaya A, Okcun B, Kucukoglu S. Dilatation of the ascending aorta and serum alpha 1-antitrypsin level in patients with bicuspid aortic valve. Heart Vessels. 2012;27(4):391-397.

17. Branchetti E, Bavaria JE, Grau JB, Shaw RE, Poggio P, Lai EK, Desai ND, et al. Circulating soluble receptor for advanced glycation end product identifies patients with bicuspid aortic valve and associated aortopathies. Arterioscler Thromb Vasc Biol. 2014;34(10):2349-2357.

18. Wheeler JB, Ikonomidis JS, Jones JA. Connective tissue disorders and cardiovascular complications: the indomitable role of transforming growth factor-beta signaling. Adv Exp Med Biol. 2014;802:107-127.

19. Forte A, Bancone C, Cobellis G, Buonocore M, Santarpino G, Fischlein TJM, Cipollaro M, et al. A Possible Early Biomarker for Bicuspid Aortopathy: Circulating Transforming Growth Factor beta-1 to Soluble Endoglin Ratio.
Circ Res. 2017;120(11):1800-1811.

20. Albinsson S, Della Corte A, Alajbegovic A, Krawczyk KK, Bancone C, Galderisi U, Cipollaro M, et al. Patients with bicuspid and tricuspid aortic valve exhibit distinct regional microrna signatures in mildly dilated ascending aorta. Heart Vessels. 2017;32(6):750-767.

21. Boon RA, Vickers KC. Intercellular transport of microRNAs. Arterioscler Thromb Vasc Biol. 2013;33(2):186192.

22. Campbell M. The natural history of congenital aortic stenosis. Br Heart J. 1968;30(4):514-526.

23. Michelena HI, Desjardins VA, Avierinos JF, Russo A, Nkomo VT, Sundt TM, Pellikka PA, et al. Natural history of asymptomatic patients with normally functioning or minimally dysfunctional bicuspid aortic valve in the community. Circulation. 2008;117(21):2776-2784.

24. Ward C. Clinical significance of the bicuspid aortic valve. Heart. 2000;83(1):81-85.

25. Bauer M, Meyer R, Bauer U, Goetze N, Lange PE, Hetzer R. [Relation of aortic wall alterations and ascending aorta diameter in patients with bicuspid aortic valve]. Z Kardiol. 2002;91(10):818-824.

26. Fazel SS, Mallidi HR, Lee RS, Sheehan MP, Liang D, Fleischman D, Herfkens R, et al. The aortopathy of bicuspid aortic valve disease has distinctive patterns and usually involves the transverse aortic arch. J Thorac Cardiovasc Surg. 2008;135(4):901-907, e901-902.

27. Januzzi JL, Isselbacher EM, Fattori R, Cooper JV, Smith DE, Fang J, Eagle KA, et al. Characterizing the young patient with aortic dissection: results from the International Registry of Aortic Dissection (IRAD). J Am Coll Cardiol. 2004;43(4):665-669.

28. Bossone E, Pyeritz RE, O'Gara P, Harris KM, Braverman AC, Pape L, Russo MJ, et al. Acute aortic dissection in blacks: insights from the International Registry of Acute Aortic Dissection. Am J Med. 2013;126(10):909-915.

29. Olearchyk AS. Congenital bicuspid aortic valve and an aneurysm of the ascending aorta. J Card Surg. 2004;19(5):462-463.

30. Fenoglio JJ, Jr., McAllister HA, Jr., DeCastro CM, Davia JE, Cheitlin MD. Congenital bicuspid aortic valve after age 20. Am J Cardiol. 1977;39(2):164-169.

31. Bauer M, Pasic M, Meyer R, Goetze N, Bauer U, Siniawski H, Hetzer R. Morphometric analysis of aortic media in patients with bicuspid and tricuspid aortic valve. Ann Thorac Surg. 2002;74(1):58-62.

32. Robicsek F, Thubrikar MJ, Cook JW, Fowler B. The congenitally bicuspid aortic valve: how does it function? Why does it fail? Ann Thorac Surg. 2004;77(1):177-185.

33. Turina J, Turina M, Krayenbuhl HP. [Significance of the bicuspid aortic valve in the incidence of aortic valve defects in adults]. Schweiz Med Wochenschr. 1986;116(44):1518-1523

34. Roberts WC. The congenitally bicuspid aortic valve. A study of 85 autopsy cases. Am J Cardiol. 1970;26(1):7283.

35. Sabet HY, Edwards WD, Tazelaar HD, Daly RC. Congenitally bicuspid aortic valves: a surgical pathology study of 542 cases (1991 through 1996) and a literature review of 
2,715 additional cases. Mayo Clin Proc. 1999;74(1):1426.

36. Shores J, Berger KR, Murphy EA, Pyeritz RE. Progression of aortic dilatation and the benefit of long-term beta-adrenergic blockade in Marfan's syndrome. N Engl J Med. 1994;330(19):1335-1341.

37. Nagashima H, Sakomura Y, Aoka Y, Uto K, Kameyama $\mathrm{K}$, Ogawa M, Aomi S, et al. Angiotensin II type 2 receptor mediates vascular smooth muscle cell apoptosis in cystic medial degeneration associated with Marfan's syndrome. Circulation. 2001;104(12 Suppl 1):I282-287.

38. Mullen M, Jin XY, Child A, Stuart AG, Dodd M, AragonMartin JA, Gaze D, et al. Irbesartan in Marfan syndrome (AIMS): a double-blind, placebo-controlled randomised trial. Lancet. 2020;394(10216):2263-2270.

39. Stewart BF, Siscovick D, Lind BK, Gardin JM, Gottdiener JS, Smith VE, Kitzman DW, et al. Clinical factors associated with calcific aortic valve disease. Cardiovascular Health Study. J Am Coll Cardiol. 1997;29(3):630634.

40. Moore P, Egito E, Mowrey H, Perry SB, Lock JE, Keane JF. Midterm results of balloon dilation of congenital aortic stenosis: predictors of success. J Am Coll Cardiol. 1996;27(5):1257-1263.

41. Roberts WC, Ko JM. Frequency by decades of unicuspid, bicuspid, and tricuspid aortic valves in adults having isolated aortic valve replacement for aortic stenosis, with or without associated aortic regurgitation. Circulation. 2005;111(7):920-925.

42. Hameed A, Karaalp IS, Tummala PP, Wani OR, Canetti M, Akhter MW, Goodwin I, et al. The effect of valvular heart disease on maternal and fetal outcome of pregnancy. J Am Coll Cardiol. 2001;37(3):893-899.

43. Silversides CK, Colman JM, Sermer M, Farine D, Siu SC. Early and intermediate-term outcomes of pregnancy with congenital aortic stenosis. Am J Cardiol. 2003;91(11):1386-1389.

44. Yap SC, Drenthen W, Pieper PG, Moons P, Mulder BJ, Mostert B, Vliegen HW, et al. Risk of complications during pregnancy in women with congenital aortic stenosis.
Int J Cardiol. 2008;126(2):240-246.

45. Tzemos N, Silversides CK, Carasso S, Rakowski H, Siu SC. Effect of pregnancy on left ventricular motion (twist) in women with aortic stenosis. Am J Cardiol. 2008;101(6):870-873.

46. Tzemos N, Silversides CK, Colman JM, Therrien J, Webb GD, Mason J, Cocoara E, et al. Late cardiac outcomes after pregnancy in women with congenital aortic stenosis. Am Heart J. 2009;157(3):474-480.

47. Roman MJ, Devereux RB, Kramer-Fox R, O'Loughlin J. Two-dimensional echocardiographic aortic root dimensions in normal children and adults. Am J Cardiol. 1989;64(8):507-512.

48. Johnston KW, Rutherford RB, Tilson MD, Shah DM, Hollier L, Stanley JC. Suggested standards for reporting on arterial aneurysms. Subcommittee on Reporting Standards for Arterial Aneurysms, Ad Hoc Committee on Reporting Standards, Society for Vascular Surgery and North American Chapter, International Society for Cardiovascular Surgery. J Vasc Surg. 1991;13(3):452-458.

49. Nistri S, Grande-Allen J, Noale M, Basso C, Siviero P, Maggi S, Crepaldi G, et al. Aortic elasticity and size in bicuspid aortic valve syndrome. Eur Heart J. 2008;29(4):472-479.

50. Grotenhuis HB, Ottenkamp J, Westenberg JJM, Bax JJ, Kroft LJM, de Roos A. Reduced aortic elasticity and dilatation are associated with aortic regurgitation and left ventricular hypertrophy in nonstenotic bicuspid aortic valve patients. J Am Coll Cardiol. 2007;49(15):1660-1665.

51. Bergler-Klein J, Klaar U, Heger M, Rosenhek R, Mundigler G, Gabriel H, Binder T, et al. Natriuretic peptides predict symptom-free survival and postoperative outcome in severe aortic stenosis. Circulation. 2004;109(19):23022308.

52. Garcia J, Barker AJ, Murphy I, Jarvis K, Schnell S, Collins JD, Carr JC, et al. Four-dimensional flow magnetic resonance imaging-based characterization of aortic morphometry and haemodynamics: impact of age, aortic diameter, and valve morphology. Eur Heart J Cardiovasc Imaging. 2016;17(8):877-884. 